\title{
IMPROVEMENT OF SERVICE QUALITY IN HIGHER PROFESSIONAL EDUCATION BY APPLICATION OF LEAN MANUFACTURING THEORY IN UNIVERSITIES
}

\author{
Valery V. Glushchenko ${ }^{1} \boldsymbol{Q}$ (iD), Irina A. Presnuhina ${ }^{2} \boldsymbol{\square}$, Ekaterina V. Samodelova ${ }^{3}$ \\ $\square$
}

${ }^{1}$ Associate professor of technical sciences, Professor of Project activities center of Moscow Polytechnic University 107023 Russia, Moscow Bolshaya Semenyovskaya str., 38

${ }^{2}$ Associate professors of philological sciences, Head of Foreign Languages Department of Moscow Polytechnic University 107023 Russia, Moscow Bolshaya Semenyovskaya str., 38

${ }^{3}$ University lecturers of Foreign Languages Department 107023 Russia, Moscow Bolshaya Semenyovskaya str., 38

DOI: https://doi.org/10.29121/IJOEST.v5.i1.2021.151

Article Type: Research Article

Article Citation: Valery V. Glushchenko, Irina A. Presnuhina, and Ekaterina V. Samodelova. (2021). IMPROVEMENT OF SERVICE QUALITY IN HIGHER PROFESSIONAL EDUCATION BY APPLICATION OF LEAN MANUFACTURING THEORY IN UNIVERSITIES. International Journal of Engineering Science Technologies, 5(1), 18-29. https://doi.org/10.29121/IJOEST.v 5.11.2021.151

Received Date: 15 January 2021

Accepted Date: 02 February 2021

Keywords:

A Service

Higher Professional Education

A Theory

Lean Manufacturing

A Model

Quality

A University

State

A Student

An Assessment

\section{ABSTRACT}

The subject of the article is the increase in service quality of higher professional education by applying the theory of lean manufacturing in universities. The object of the article is the service delivery process of higher professional education. The purpose of the article is the increase in quality services of higher professional education in universities. We solve the following problems to achieve the stated objective: we investigated the role of service quality of higher professional education in the innovational development of real economics, creating the method of using the theory of lean manufacturing in university performance, formation of the model for quality assessment of lean manufacturing theory in universities. The methods of scientific research are the theory of lean manufacturing, synthesis and analysis forecasting and design, a systematic approach, expert assessments, retrospective and comparative analysis, predicative analysis. Scientific novelty of the work is represented by the results reflecting the increase in service quality of higher professional education based on the theory of lean manufacturing, the methodology of using lean manufacturing principles for increasing the quality of educational services, synthesis of a four-level model of higher professional education services. 
Valery V. Glushchenko, Irina A. Presnuhina, and Ekaterina V. Samodelova

\section{INTRODUCTION}

The relevance of the article is related to the fact that the increase in service quality of higher professional education is a vital factor of social economic development in postindustrial conditions.

The hypothesis of this article is the assumption that the increase in service quality of higher professional education can be achieved with the help of lean manufacturing theory in the performance of postindustrial universities.

The purpose of the article is to increase the service quality of higher professional education in postindustrial universities.

The following tasks are solved to achieve the stated purposes:

- investigating the role of higher professional education in innovative development of real economics;

- creating methods of applying principles of lean manufacturing theory in university performance;

- making the model for assessing the efficiency of lean manufacturing theory in universities.

The object of the article is the process of service delivery in higher professional education in postindustrial universities.

The subject of the article is the increasing service quality of higher professional education by lean manufacturing theory

Methodological principles of lean manufacturing theory are being highly developed in the $21^{\text {st }}$ century for finding the way out of global crisis [[1], p.642-647].

The analyses of the success of the automobile company Toyota showed that the basis of its market success is the management model developed in the company which is based on minimization of losses and its application in practice [[2], p.3]. Practical success of this business model led to its active investigation and attempts to copy the methodology of lean manufacturing [[2], p.; [3], 3, p.2]. At the same time lean manufacturing was represented as a number of practical recommendations until now. Attempts to imply these principles are not always successful. One of the reasons (the sources of implementation risks) is that theoretical bases of lean manufacturing are not developed yet. Some mistakes of implementing the lean manufacturing are possible due to some knowledge gaps. This became the reason for attempts to develop the general theory of lean manufacturing (theory of thrift) [[3], p.4349, [4], p.43-49; [5], p. 135-137]

Researches express an opinion that it is necessary to organize studies in universities on the basis of lean manufacturing recommendations [[5], p. 78-81] and to use lean manufacturing as a tool for managing the service quality in higher professional education [[6], p. 304-310;[7], p. 15-20].

Basics of conceptual approach to lean higher education are being developed. [[8], p.55-59; [9], p.240-256].

Experts draw attention to the fact that it is necessary to develop the philosophy of lean manufacturing and practical changes in functioning policy of universities for providing efficiency of lean manufacturing methods in the context of university performance. [[10], p.998-1001; [11], p, 96-112].

Researches search the basis for using project approach while implementing lean manufacturing in university management [[12], p.104-115].

At the same time lean technologies (lean manufacturing) is considered to be a tool for development of universities [[13], p.272-277]. 41].

Future perspectives and issues of using technologies in university performance are being studied [[14], p.36-

There is a point of view that students' government bodies must influence the process of implementing lean technologies [[15], p.58-68]. In fact, the analysis of using lean manufacturing principles shows that any organization (including universities) must switch to using implicated (participatory) management for effective usage of lean manufacturing technologies.

The main approach to managing the production of educational services is described in the paper [[16], p. 922].

At the same time researches from regions suppose that the development and using of lean-technologies in a university is crucial factor for the development of not only the university itself but it is also a key factor for socialeconomic growth of a region in general [[17], p. 153-156]. Such conclusion of regional researches can be connected with the process of transmission (multiplication) of lean manufacturing organizational culture into the real 
Improvement of Service Quality in Higher Professional Education by Application of Lean Manufacturing Theory in Universities

economics of regions with the help of transferring university graduates' values into the work practice of economic agents.

We can admit useful the further development of organizational culture and methodology of lean-manufacturing and technologies in university performance [[18], p.298-322].

In general, the analysis of the research results in lean-manufacturing represented in the article reflects the following:

- using lean manufacturing is considered to be an important element of the system which provides competitiveness of organizations in any fields;

- the methodology of lean manufacturing is represented by a number of practical recommendations for eliminating sources of losses and a list of lean manufacturing principles;

- the following factors appear in practical implementation of lean manufacturing: the risk of knowledge which is associated with the incomplete knowledge about the mechanism of the impact of lean manufacturing principles on the economic and financial mechanism of an organization (a university in particular); the risk of action defined by incorrect application of the known principles of lean manufacturing methodology in a university;

- bureaucratic model of university management can be one of the obstacles and source for the risk while implementing lean manufacturing, that is why the transition to implicated (participatory) management in universities is essential;

- it is necessary to form the mechanism of educational quality improvement based on adaptation and further development of lean manufacturing methodology to ensure the efficiency of lean manufacturing methodology in universities.

The analysis of research results and present performance of modern Russian universities allows us to highlight the following aspects as sources of losses for the quality of higher education:

- inefficiency of recruitment procedures according to their scientific qualifications and their pedagogical skills because of flaws in competition legislation, competitive positions, competitive culture in universities;

- lack and poor development in management systems of social advancement of scientific and pedagogical staff in universities which leads to incomplete use of scientific and pedagogical workers' potential in universities;

- poor development of the lean manufacturing idea in universities under dominating bureaucratic management system which hampers formation of lean-mechanism in universities;

- lack of motivation among the university administration to introduce lean-philosophy and lean-mechanism, the system of lean manufacturing in full etc.

\section{METHOD}

By lean mechanism for increasing the quality of education in universities let us agree to accept a systematic unification of principles, methods, means and tools of lean manufacturing which are used for reaching this goal in a university. We can denote that analysis and synthesis, systematic analysis and approach, predictive and comparative analysis, diagnostics, forecasting and expert assessments etc. are the methods of formation of lean mechanism for improving the quality of education in universities.

By the efficiency of lean methods, tools of lean manufacturing in a university we should understand the ability of these principles, methods and tools to reach the set point (or the maximum) level of education quality for a certain period of time spending no more than a certain amount of resources.

Let us study the role of higher education in the management mechanism of innovative social-economic development of national economics to assess the importance of implementing lean manufacturing methodology in universities. We suggest the research based on the three steps:

- determining factors of lean manufacturing which influence the quality of education and organizational culture in real economics:

- describing the mechanism of influence of these lean manufacturing factors on the quality of education and real economics;

- examining the results of the impact of lean manufacturing factors on social-economic development at the regional and/or state level. 
We can underline the following factors of influence of lean technologies on the quality of higher education and pace of social-economic development of an industry and/ or a region:

- fixing the rules in regulatory documents for conducting a competitive selection of scientific-pedagogical workers for filling vacancies and/or lecturing key training courses based on objective criteria of estimation (academic degree, title, availability of publications, experience of pedagogical work, availability of methodical innovations and know-how and etc) which will allow to rise competence of graduates;

- revealing scientific-pedagogical workers' (SPW) potential on the basis of own scientific researches and their integration into the training process in a pleasant creative atmosphere by game approach in teaching and up-bringing. It will rise competence of graduates and it will make a creative approach become one of the key values for the staff in real economics;

- regulating all kinds of workload like classroom load, methodical, scientific work of all SPW for rising efficiency of knowledge sharing from SPW to a trainee (for example in the "leader-follower" model). It will create more preferable conditions for all scientific-pedagogical staff of a university (not only its' individual representatives) which will allow to increase the competence of graduates and it will consolidate the principle of workload regulation as the key value of organizational culture of lean-technologies in universities and economics;

- shifting the focus of knowledge transfer from SPW to a student to collaboration between them in the process of joint scientific researches integrated together with teaching and up-bringing. It will allow to master the techniques of self-actualization not only for SPW but for students as well in both the processes of training and in the following practical work in real economics;

- transfer of key values based on lean technologies from SPW to a student and later into real economics during collaborative work and up-bringing. It will allow to reduce losses in real economics and by this means it will help to fasten the pace of social-economic development;

- formation of philosophy and organizational culture of lean manufacturing for all participants of lean education and integration of this culture (multiplication of lean-culture) into economics and etc.

- Lean mechanism is a systematic unity of principles, means, methods and tools of lean manufacturing based on a particular philosophy: We should remember the following factors while creating lean-mechanism of increasing quality service of higher professional education:

- formation of the society and knowledge economy in our country [[19].p.812].

They will be identified by the idea that the development of society and economics by $70-80 \%$ appears on the basis of the intensification of knowledge acquisition and/or the increase in the efficiency of knowledge usage;

- the influence of implicit knowledge is growing as a result of formation and analysis of social-economic systems [[20], p.800]. This knowledge characterizes emergence of systems and processes of aggregating subsystems into the system related to it and a reversed process of decomposition (subdivision) of a system into its subsystems, blocks and elements;

- fastening scientific-technical progress and the fact that the knowledge volume necessary for a successful activity in real economics is increasing;

- increasing the rate of scientific and technological progress and due to it fastening the process of knowledge outdating and etc.

Great influence of implicit knowledge on the service quality of higher professional education must correlate with understanding of the fact that implicit knowledge cannot be consolidated and transferred by verbal methods in a university during educational process. Transfer and acquisition of implicit knowledge is realized in nonverbal communications of SPW and students during educational process. Herewith the role of implicit knowledge, nonverbal communications is increasing because it is through the use of implicit knowledge that there is a possibility of getting synergetic effect in economics and social development.

Students' level of creativity becomes one of the main criteria of estimating the service quality of higher professional education in the context of informational technologies development and environmental mobility of organizations [[21], p.26-30]. The Environmental mobility is defined by continuous global crisis. Creativity is interpreted as individual employee's ability to professional creativity [[22], p.14] 
Improvement of Service Quality in Higher Professional Education by Application of Lean Manufacturing Theory in Universities

Experts suggest using a four level model of educational products (services) of universities for increasing the level of objectivity and diagnosing the service quality of higher professional education: the first level of the model describes the main purpose of a product - a systematic assimilation of knowledge, skills (competencies) and organizational culture; on the second level of the model being discussed we describe some results of acquired education and upbringing (this is a number of competencies, values of organizational culture); the third level describes "reinforcement" of the product (availability of budgetary places, dormitories, a possibility to study on credit etc.); the forth level of the educational product model characterizes its ecological and strategic meaning, including its impact on demographic, social, cultural processes in society and economics [[18], p.298-312].

The usage of this model in the formation of lean mechanism allows increasing the level of validity of service quality in higher professional education in a university. It also helps to find weak points in service quality of education, reduce losses in educational process, and realize purposeful management of service quality in higher professional education. Let us focus on the named ways of using the four-level model of higher educational. The fourlevel model of assessment service quality of higher professional education can increase the level of validity quality assessment in higher education in a university by structuring components of education level received and in particular selection and assessment of such components:

- on the second level of the model this is the volume of knowledge received, creativity of thinking, scientific research skills, performance and presentation experience, the level of business communication and etc.;

- on the third level of the model this is the possibility of studying on expense of the budget or a credit for education, dormitories for foreign students, exemption from military service etc;

- on the fourth level this is the strategic development of economic industries and society in general by registration and assessments of factors influencing educational technologies on a human ecology. This approach allows us to estimate the degree of losses in the service quality of educational process in university.

Let's take the term "quality of higher education" as a quality that meets the requirements of employers and / or university graduates.

Usage of the taken four level model will let us find weak points in quality of higher education, for example as a result of comparing assessments factors of higher education quality in a particular university with assessments of rival universities or on average in the particularly taken segment. This will give us the opportunity to make a comparative analysis of losses in service quality of higher education in rival universities or in industry specified universities.

So, finding losses in service quality, troublesome factors in higher education on the of basis of their assessments make conditions for intra-university programmes of lean mechanisms for service quality development. These mechanisms are built on purposeful management of service quality in higher professional education for increasing the level of thrift of educational processes in universities, growth of university competitiveness.

Methodological foundations of general thrift theory in higher education are represented in the article [[18], p.298-322]. They can be useful for development of conceptual framework of improving service quality of higher

professional education.

Competitiveness of universities for applicants, regularly (for example yearly) expert assessments of the service quality of education in university by graduates as well as employers can become the mover of lean mechanism development for increasing service quality of higher professional education.

The starting point for formation of this mechanism in performance of universities becomes philosophic conception of lean methodology.

The philosophical concept of increasing service quality in higher professional education based on lean methods is interpreted as a systematic wise approach to the essence, content of the mechanism and its specifics in the conditions of postindustrial higher education. Here we also take into account systematic links of higher education to real economics, life of society.

The philosophy of forming mechanism for the increase in service quality of higher professional education can be understood as a general approach to the essence, specifics of usage of lean manufacturing methods in the performance of postindustrial universities. 
We accept the following points by the ideology of increasing educational level based on lean manufacturing methods: first of all, this is the main idea of its formation; secondly this is the means of power distribution (posts and personal authority) while creation and functioning of such a mechanism, its elements.

We suggest a system of events devoted to creation and provision of an efficient functioning of the mechanism to be treated as the policy of formation and functioning of the mechanism for increasing service quality in higher professional education based on lean manufacturing methodology.

Philosophical and cultural basis of creative approach while forming the mechanism for the increase in service quality is provided by self-consciousness and culture of participants [[23], p.3-10].

Philosophy of increasing service quality of higher professional education on the basis lean approach is innovational and it involves the necessity of organizational and methodological changes in the performance of a university for solving problems of increasing the service quality of higher professional education due to implication of lean manufacturing methods.

Let us agree to take into consideration the results of work [[9], p. 240-256; p.24-26] while forming practical mechanism of increasing the service quality of higher professional education based of lean manufacturing methodology in educational performance of universities. Let us accept constant intension of university staff to eliminate all kinds of losses as lean manufacturing of educational products in a university. It is built on the involvement of various managers, scientific-pedagogical and other workers of universities into the process. At the same time, we will call a loss any kind of university performance which does not lead to increasing service quality of education and/or competitiveness of universities.

Lean mechanism of increasing service quality of higher professional education in a university is oriented to analysis, diagnosis and elimination of such sources of losses.

1) Overproduction can be treated in various aspects in the field of higher education. First of all, this is overproduction which means issuing an excess number of particular graduates. Only $40 \%$ of graduates work in their specialty according to expert estimations. Lean tools of this kind of losses can be the following: indicative industrial staff planning realized by a university together with state institutions and/or public organizations of employers; market tools, for example forward contracts, long term agreements for targeted training of students with not only state institutions but also with commercial structures and etc. Secondly the source of this kind of losses in universities can be overproduction of science knowledge. It appears because of "spreading" and/or inconsistency of scientific research themes to scientific needs of basic enterprises and/or to the content of educational process. Lean instruments for minimizing this kind of losses can be scientific-educational warrants (derivative securities), agreements made between a university and main enterprises of the field. These agreements concern long-time collaboration including a list of scientific services (overviews, articles, developments) which are regularly represented by universities to their basic organizations.

2) Another kind of losses which got the name "unnecessary movements" in lean methodology can be treated as often possible competitions for SPW. They distract scientific and pedagogical staff from scientific educational process in university. Lean instruments for reducing this source of losses can be scientific researches for optimizing durability of contracts with SPW in such a way that they do not initiate unnecessary movements and they do not reduce scientific-pedagogical staff's motivation for increasing the service quality of education. They also they do not allow "ossification" of a university's organizational structure which can lead to indifference to pedagogical innovations and their changes in the educational services market.

3) Such source of losses as "unnecessary transportation" in higher education can be also treated in different ways. First of all, it can be a quite often change of scientific disciplines which is given by SPW. It does not allow to achieve maximum quality of educational process (it is practically known that high quality of scientific process is achieved after three course readings) Secondly "unnecessary transportation" can appear due to suboptimal course sequence. It makes SPW duplicate a significant part of knowledge. For example, if the educational course "methods of analysis in management" is given earlier than the course "methods of management" itself. Thirdly this can be unreasonable change of classrooms which deprives SPW of having rest and makes SPW distract their attention to changing classrooms and extra adaptation to workplace after the change during the breaks between classes. Lean tools of reduction of this kind of source of losses can be planning and rationing the named areas (frequency of course updating, sequence of optimization and logics for courses, schedule optimization). 
Improvement of Service Quality in Higher Professional Education by Application of Lean Manufacturing Theory in Universities

4) The source of losses which is treated like "excessive stock" can happen at the department or university in the following situations. First of all, the source of losses connected with "excessive stock" can be breaking the principal (which is famous for any scientific organization) of using the staff in their highest qualification. This can be reflected in the fact that the less qualified SPW of a department are assigned to lecturing key courses, coursework guidance or diploma guidance. An "excessive stock" of scientific-pedagogical potential can be created artificially as a result of such a subjective distribution of workload. These "excessive stocks" mean that available potential isn't used efficiently for increasing the service quality of higher professional education. Secondly "excessive stock" can appear when the development of one and the same methodological provision is given to several SPW. This can lead to multiplication of SPW labor costs for creation of methodological provision. Lean tools for minimizing this source of losses can be planning and arrangement of SPW according to the courses being lectured on the principle of using staff with maximum qualification. The tool for minimizing this loss can be also planning provision of methodological developments excluding their duplication and discussing methodological materials on the department meetings for increasing the service quality of higher professional education.

5) "Excessive possessing" as a source of losses can be treated as an erroneous wrong subjective (in the interests of particular SPW) workload distribution to academic disciples of specialty. As a consequence, SPW and students carry out a larger volume of work than it is necessary for an employer (a customer) keeping in mind the specifics of his performance and production issued. Lean tool of reducing this type of losses can be implementation of a product model of higher education [[25], p.37-56]. As a result, there is a more exact specification of necessary volumes of knowledge while manufacturing specific production for basic organizations of university. It is recommended to create a "product tree" for basic organizations of a university for minimizing losses in the context of source "excessive processing". For example, a product tree for an automobile enterprise can be the following: on the first the highest level there is the process of vehicle operation; on the second level this is an automobile itself and the system of technical service; on the third these are blocks of a vehicle and its systems of technical service and etc. Later we define "the weight" of each component in the performance of basic enterprise of a university. Then we define an optimal number of academic hours given to corresponding academic discipline which leads to minimizing "excessive processing" of students in educational process.

6) "Waiting" as a source of losses service quality in higher professional education can be connected with the lack and/or delay (in poorly responsive structure of university) of information about new scientific progress, new pedagogical methods, new technical sources of teaching, impact of components of academic process on higher education quality. Lean tools of minimizing this source of losses can be maintaining of professional expert feedback between a university and graduates and employers. This tool can also be increasing receptivity of an organizational structure in a university to changes in external and internal environment. For example, it can be realized via transition to matrix system of university management in such a way that production part of matrix is responsible for compliance of the service quality in higher professional education with requirements of customers. The functional part of matrix is responsible for recruitment and the level of particular disciplines. Criteria of minimizing the losses from "waiting" can be scientific publications of SPW on the given disciplines; implementation of such publications into the academic process; joint publications of SPW and students on the disciplines being read.

7) "Readjustment of flows" as a source of losses in higher education can be reflected in a number (percentage) of students expelled from university and/or graduates whose competence or organizational culture can be estimated as unsatisfactory by students themselves or their employers. The reason for this source of loss can be low efficiency of feedback between a university and graduates and/or employers, insufficient career guidance, little motivation of students, low level of pedagogical skills. This does not allow to timely diagnose psychophysical features of students and to change adequately methods of education (as it is required in the letter from Ministry of Education from 06.02.2014 № 09-148).

8) Unused potential of staff as a source of losses in higher education can be reflected in the following: a regulatory framework of modern competitive order in university contains flaws which let universities subjectively abandon employees with higher potential. As it was stated earlier in case of subjective violation of principle of using SPW in maximum qualification the level of students' knowledge will be lower because they were taught by less qualified SPW and potential of more qualified SPW is not used fully. Another reason 
for it is that sometimes scientific and methodical developments of SPW are not used in the process of education. The elimination of flaws in the system of motivation for administration staff and SPW can lead to increase in the service quality of higher professional education etc.

9) More over in the article we suggest defining the ninth source of losses in performance of organizations specifically "underdevelopment of philosophy and culture" of lean education in universities. The importance and impact of this source is defined by the fact that according to expert estimations from $80 \%$ to $90 \%$ of all processes in organizations has an informal basis. That is why low level of philosophy and organizational culture of lean mechanism can be a source of losses in service quality of higher professional education. And vice versa the development of philosophy and culture of lean education increase in the service quality of higher professional education due to implicit knowledge, informal methods and relations in a university.

The known principles of lean manufacturing were formulated for minimizing these and those kinds of losses. These principles concern university performance in the frames of lean mechanism increase in service quality of higher professional education. We suggest interpreting these principles in the following way:

1) it is necessary to search for a harmonic compromise between strategic aims and current profit of a university on the basis and keeping in mind the mission, vision and concept of university development while making management decisions;

2) the process of lean mechanism development for increasing service quality of higher professional education must be nonstop. Production links between all participants of this process must be strengthened for timely and even proactive detection of problems;

3) it is necessary to use the "pulling system" (to reduce the risk of over-production of graduates) for supporting feedbacks between basic organizations of a field; indicative planning of need for staff, using of targeted training, forward contracts for preparing specialists, using scientific-educational warrants of universities;

4) it is recommended to distribute the volume of educational workload equally in such aspects (between training courses, semesters, SPW). It is also vital to avoid overloading of some SPW in comparison with another in all kinds of scientific, methodical, educational performance;

5) it is important to make up-to-date substantive modernization of educational programmes and staffing policy a part of production culture to prevent the stop of specialist's graduation because of the critical decrease in the quality of education;

6) functioning of the lean mechanism for increasing the service quality of higher professional education in university can be standardized due to standardization of tasks being solved and delegating necessary authorities to particular departments and executives; decomposition and following standardization can be realized via a list of tasks for minimizing kinds of losses (8 sources) and /or formatting tasks of maximum efficiency in realization of principles (14 principles) of lean manufacturing;

7) one should use simpler visual means for transfer of knowledge and values to students and control of their understanding in educational process. One should not use computer technologies if they distract a student's attention from comprehension of subject study essence. education.

8) One should use approved reliable technologies in education and upbringing. Innovational process and development of educational technologies must take into account the presence and significance of implicit knowledge during studies and real practice. This knowledge cannot be transferred by verbal methods in informational technologies. New technologies must be implied after their testing and assessment of their efficiency in increasing the service quality of higher professional education;

9) It is highly recommended to bring up leaders who share the concept, know well educational process based on lean mechanism of increasing service quality of higher professional education and those who are able to develop and adapt this mechanism creatively in conditions defined by scientific-technological progress and/or global crisis and can also teach this to other people;

10) Personnel policy and personnel management system of a university must be aimed at formation of organizational culture and project teams practicing this culture. The teams should be able to provide functioning of lean mechanism and lean technologies in a university for meeting challenges of increasing service quality of higher professional education;

11) University administration should respect their partners (SPW, students, employers) in creation and provision of lean mechanism functioning for increasing service quality of higher professional education. 
Improvement of Service Quality in Higher Professional Education by Application of Lean Manufacturing Theory in Universities

University administration should also set difficult tasks for SPW and help them improve while solving problems of increasing the service quality of higher professional education;

12) It is highly recommended to see everything (curriculums, work programmes of academic disciplines, workload distribution of SPW, schedule of SPW and other) with your own eyes (genti genbutsu) for analyzing the efficiency of lean mechanism funtioning. In this case emerging opinion will not be superficial;

13) One should make decisions relying on joint discussion of all possible kinds of actions and their consequences for service quality of higher proffesional education. These decisions are taken by subjects of educational process (university administration, SPW, students, employers, state control bodies). In case when a decision was made it is significant to imply it without any delay considering possible risks (nemavasi);

14) A university must become not only educational but also self-taught structure due to self-analysis (hinsey) and continuous perfection (kaidzen) of lean mechanism for increasing the service quality of higher professional educational in university.

The following model can be suggested for assessing efficiency of lean mechanism for increasing service quality of higher professional education:

$\mathrm{K}_{\text {лин }}=\mathrm{K}_{\text {во }} * \mathrm{~K}_{\text {пп }} * \mathrm{~K}_{\text {лд }} * \mathrm{~K}_{\text {нт }} * \mathrm{~K}_{\text {из }} * \mathrm{~K}_{\text {ио }} * \mathrm{~K}_{\mathrm{o}} * \mathrm{~K}_{\text {пб }} * \mathrm{~K}_{\text {нп }} * \mathrm{~K}_{\text {ок; }}$;

Where

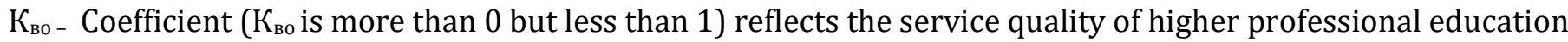
in a university which does not use lean-mechanism for increasing quality of higher education;

$K_{\text {пп - }}$ a multiplier $\left(K_{п п}\right.$ is more than 1$)$ which reflects growth in service quality of higher professional education due to reducing "overproduction" of unused scientific knowledge;

$\kappa_{\text {лд }}$ - coefficient $\left(K_{\text {лд }}\right.$ is more than 1$)$ which reflects improvement of service quality in higher professional education due to reduction of losses as a decrease of "unnecessary movements" in educational process based on lean-technologies;

$K_{\mathrm{HT}}$ - coefficient ( $K_{\mathrm{HT}}$ is more than 1 ) which reflects growth in service quality of higher professional education level due to reducing losses as a result of decreasing actions attributed to the concept "unnecessary transportation" in educational process based on lean mechanism;

$\kappa_{\text {из }}$ - multiplier ( $\kappa_{\text {из іs }}$ more than 1 ) connected with the growth of service quality in higher professional education based on loss reduction as a result of minimizing losses which refer to "excessive stock" in training process based on lean methodology;

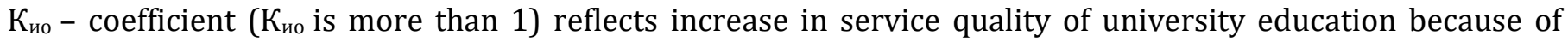
reduction of losses in education quality which are typical to the source "excessive processing" in education based on lean philosophy;

$K_{0}$ - multiplier $\left(K_{0}\right.$ is more than 1$)$ connected to the growth of service quality in higher education due to reduction of losses from "waiting" source in educational process based on lean mechanism;

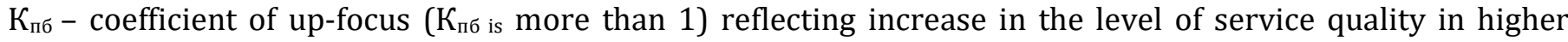
education due to reduction of losses in source "readjustment of flaws" as a lean approach;

$K_{\text {нп }}$ - coefficient $\left(K_{\text {нп }}\right.$ is more than 1$)$ messaging about increasing quality of higher professional education due to reduction of losses in service quality of education defined by the source "unused potential of staff" in lean mechanism functioning in a university;

$\kappa_{\text {ок }}$ - coefficient $\left(K_{\text {нп }}\right.$ is more than 1$)$ reflecting growth of service quality in higher lean education owing to the development of philosophy and organizational culture of such education and eliminating the source of losses connected to poor development of lean culture in practice.

At the same time if values of the named coefficients are relatively not so high, then the assessment of increasing service quality of higher professional education while implementing of lean mechanism will be achieved by summing these coefficients. For example, if we suggest that implementation of lean mechanism in each 9 sources of losses coursed the improvement in service quality of higher professional education for $3 \%(0,03)$ than the total increase in service quality of higher professional education will be $3 \% * 9=27 \%$.

All named coefficients can be received expertly by questioning the subjects of services of education (university administration, SPW, students, employers).

Simultaneously differences in such expert assessments from other subjects can become an important source of information and they can be used for diagnostics of lean mechanism of higher education. 


\section{DISCUSSION}

Materials of this article show that creation of lean mechanism manufacturing in universities can be treated as an effective tool for increasing service quality of domestic higher education without any extra-large costs.

At the same time creation and functioning of such mechanism in universities can have positive effect on socialeconomic development of a university, national economics and society in general.

Positive input of lean mechanism into development of national economics can be related to both increasing graduates' competence and distribution (multiplication) of lean manufacturing culture from universities to real economics.

Favorable influence of lean mechanism on the development of society can be defined by the fact that such education will contribute to minimizing losses of society (in particular sources) and a fuller reveal of individual employees' potential as well as scientific technological potential of society in general.

Materials of this article allow us to turn the work on creation of lean mechanism into practice.

Sequence of actions on creation of lean mechanism in universities can be the following:

- Making decision about switching to the use of lean mechanism of increasing service quality of higher professional education by governing bodies of a university (rectorate, Academic Council) and/or governing bodies of the industry;

- Fixing the functions of analyzing and minimizing the sources of losses described in this article for a particular structural element (for example, minimizing losses associated with an overproduction of graduates can be assigned for the department of target contracts and losses associated with unused scientific developments can be assigned for the office of Vice- rector of Research. The work on minimizing losses from the source "unnecessary movements" can be assigned for educational and methodological department etc. Functions responsible for compliance of lean manufacturing principles can be fixed similarly;

- Checking out functioning of the lean mechanism for increasing service quality of higher professional education;

- Monitoring functioning and estimation of lean mechanism efficiency;

- Monitoring influence of universities transition to lean technologies and to pace and quality of social economic development of a country.

Simultaneously possible difficulties and risks for realization projects and implementation of lean mechanism in universities can be the following:

- Inadequate level of motivation for university administration to implement methodology of lean manufacturing in universities;

- Lack of fixed criteria for the level of thrift in educational performance of universities;

- Ambiguity of the notion "quality of higher education" when it is interpreted by different subjects of the process etc. The fact is that the implementation of the principles of lean production, in particular the principles of "see with your own eyes" (genti genbutsu) or the principle of comprehensive discussion of problems by all participants in the process (nemavasi), may not correspond to the widespread organizational culture in universities, which is described in [[16], P.922]. This can be an important obstacle and risk.

\section{CONCLUSION}

We analyzed factors of increasing service quality of higher professional education on paces and specifics of social economic development. We described sources of losses and interpreted principles of lean manufacturing regarding specifics of university performance. We suggested the model for assessing efficiency of lean mechanism functioning in educational performance of universities. We described algorithm of formation and risks of implementing lean mechanism into the performance of postindustrial universities. 
Improvement of Service Quality in Higher Professional Education by Application of Lean Manufacturing Theory in Universities

\section{SOURCES OF FUNDING}

This research received no specific grant from any funding agency in the public, commercial, or not-for-profit sectors.

\section{CONFLICT OF INTEREST}

The author have declared that no competing interests exist.

\section{ACKNOWLEDGMENT}

None.

\section{REFERENCES}

[1] Kanyukova V.P. Lean manufacturing: main tools and principles of lean production// Science alley, 2018, V. 1 № 7 (23) - Pp. 642-647.

[2] Liker D. Dao Toyota: 14 principles of management of the leading company in the world / Jeffrey Liker; TRANS. - Moscow: Alpina Business Books, 2005. - 402 p.- (Series "Management Models of leading corporations").

[3] Glushchenko V. V., Glushchenko I. I. Conceptual aspects of lean manufacturing of goods and services//Competence. 2017. No. 6 (147). Pp. 43-49.

[4] Gryzunova S. V., Mihneva E. A., Krechetova L. V. the Modern concept of "lean production"//In book: Modern trends of development of education, science and technology, collection of scientific works on materials of VI international scientific-practical conference. Under the General editorship of A. V. Tugolukov. 2018. Pp. 135137

[5] Chernik M. V., Drokina N. N. organization of the educational process through the prism of lean production approaches / / in the collection: Innovations and prospects of modern science. Economic Sciences Collection of works of young scientists. Astrakhan, 2018. Pp. 78-81.

[6] Sharonina L. V., Bricheeva N. N. quality Management of higher education on the basis of the concept of "lean learning" / / in the collection: Proceedings of the Congress on intelligent systems and information technologies "IS\&IT 2013" Scientific edition: in 4 volumes. Ministry of education and science of the Russian Federation, Russian Association of artificial intelligence, southern Federal University. 2013. Pp. 304-310.

[7] Borisova Zh. E. the Use of national standards of lean production to improve the quality of higher education / / Economics, management and Finance in Russia and abroad. 2016. No. 3. Pp. 15-20.

[8] Tagirova A.V. The concept of lean production in the field of higher education/ / in the collection: education System and technologies of lean production Materials of full-time regional scientific and practical conference. 2017. Pp. 55-59.

[9] Glushchenko V. V., Glushchenko I. I. Conceptual approach to management of development of lean higher professional education. Bulletin of science and practice. 2017. No. 3 (16). Pp. 240-256.

[10] Kovalenko A.V. Development of philosophy of lean higher education. Forum of young scientists. 2018. No. 12-2 (28). Pp. 998-1001.

[11] Akmaeva R. I., Lunev A. P., Mineva O. K., Fadina A. G., Tomashevskaya Yu. N. Practice of application of philosophy of lean production in the organizations of higher education / / Bulletin of the Astrakhan state technical University. Series: Economics. 2019. No. 1. Pp. 96-112.

[12] Gaivoronskaya S. A. the Practice of introducing lean technologies into the management system of the University: project approach/ / University management: practice and analysis. 2019. T. 23. No. 4. Pp. 104115.

[13] Groshev A. R., Dubrovskaya E. N. Lin-technologies and development of the University/ / Kant. 2019. No. 3 (32). Pp. 272-277. 
[14] Konnova A.V., bykanova N. I. Problems and prospects of lean technologies application in higher educational institutions/ / in the collection: Project and lean synergy as a factor of labor productivity increase (education). Under the editorship of L. A. Simakova. 2018. Pp. 36-41.

[15] Kireeva O. A., Varenichenko N. In. Pigolenko L. A. the Role of student government in the implementation of lean in higher education//In the book: Science. Culture. Art: actual problems of theory and practice collection of materials of the all-Russian (with international participation) scientific and practical conference: in 4 volumes. 2019. Pp. 58-68.

[16] Balatsky E. V., Verevkin O. L. "Bureaucratic model of" success of Russian economic universities" / / Vestnik RAS, 2015, No. 10, p. 922.

[17] Pletneva T. V. the Role of integrating the resources of the University and organizations in the region in the application of lean techniques for the development of socio-economic potential of the Udmurt Republic//In collection: PROBLEMS AND prospects of DEVELOPMENT of SOCIO-ECONOMIC POTENTIAL of RUSSIAN REGIONS materials of VII all-Russian scientific-practical conference. Chuvash state University named after I. N. Ulyanov. 2018. Pp. 153-156.

[18] Glushchenko V. V., Glushchenko I. I. Methodology and organizational culture of improving the quality of education in higher education on the basis of the theory of thrift in the development of the knowledge economy. Bulletin of science and practice. 2018. Vol. No. 7. Pp. 298-322. Mode of access: http://www.bulletennauki.com/v-glushchenko (accessed 15.07.2018). DOI:10.5281/zenodo.1312241.

[19] Karpov A. O. Basic theoretical concepts of knowledge society / / Bulletin of RAS, 2015, No. 9, p. 812

[20] Tsvetkov V. Ya., Sigov A. S. Implicit knowledge: oppositional logical analysis and typologization" / / Vestnik RAS, 2015, No. 9, p. 800.

[21] Matraeva A.D. Development of students ' creativity: managerial aspect / / Sociodynamics. - 2017. - No. 10. Pp. 25-36. DOI: 10.25136/2409-7144.2017.10.24304. URL: http://e-notabene.ru/pr/article_24304.html.

[22] Guilford George. Three sides of intelligence. Psychology of thinking. - Moscow: Progress, 1965.-14 PP.

[23] Alekseeva I. Yu. Scientific philosophy as "cultural system" (about Vladimir Nikolaevich Ivanovsky and his ideas) / / Questions of philosophy, No. 11, 2012, pp. 3-10.

[24] Glushchenko V. V., Glushchenko I. I. Improving the quality of education based on the application of the principles of lean higher education / / Competence, 2018, No. 2(153), pp. 24-26.

[25] Glushchenko V. V. Product model of functioning of universities in higher engineering branch of education / / Kazakhstan Science Journal, 2019, No. 10(11), vol., pp. 37-56.

https://

sciencejournal.press/sj/article/view/121/111. 